\title{
Relationship of the sacral slope with early gait derangements in robust older women
}

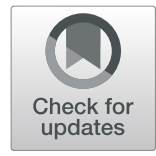

\author{
Leda Magalhaes Oliveira', Suely Roizenblatt ${ }^{2^{*}}$ D, Flavio Duarte Silva ${ }^{3}$, Arnaldo Roizenblatt ${ }^{4}$, \\ Artur Rocha Correa Fernandes ${ }^{3}$ and Vera Lucia Szejnfeld ${ }^{1}$
}

\begin{abstract}
Background: Trunk pelvic dissociation is fundamental to the compensatory mechanism for muscle weakness during body bending. We carried out an early investigation of gait changes in a sample of community-dwelling women $\geq 60$ years without gait complaints. The primary objective was to correlate spine and pelvic angles with performance tests and accelerometry parameters. The secondary objective was to correlate performance tests with accelerometry.
\end{abstract}

Methods: In this cross-sectional study, 54 community-dwelling women $\geq 60$ years were subjected to Falls Efficacy Scale-International (FES-I), performance tests (Berg Balance Scale, Timed Up and Go, and Gait analysis), and radiographic analysis of sagittal alignment (Thoracic and Lumbar Cobb, Pelvic Incidence, Sacral Slope, and Pelvic Tilt angles). Gait speed was assessed in a 10-m comfortable walk, and accelerometry parameters were obtained in a 30$\mathrm{m}$ walk distance.

Results: The sample, aged $72 \pm 6$ years, exhibited moderate correlation between Sacral Slope and Step Length (+ 0.615). Sacral Slope weakly correlated with FES-I (- 0.339), Berg Balance Scale $(+0.367)$, and with further accelerometry data in the AP plane: RMS, $(+0.439)$ and Stride Regularity $(+0.475), p<0.05$, all. Lumbar Cobb weakly correlated with the following accelerometry data in the AP plane: Step Length (+ 0.405), RMS, (+ 0.392), and Stride Regularity $(+0.345), p<0.05$, all. Additionally, Stride Regularity in AP moderately correlated with FES-I (0,561, $p<0.05)$, among other weak correlations between performance tests and accelerometry data in AP.

Conclusions: Early alterations in Sacral Slope and gait abnormalities in the AP plane may provide understanding of the early gait changes in robust older women.

Keywords: Gait; disability, Spinal curvatures, Pelvis, Aging

\section{Background}

With ageing, a compensatory mechanism to the alignment derangement between pelvis and trunk occurs as a deliberate strategy to overcome the decrease in muscle strength [1]. Since the walking function requires integrity and fine-tuning of various body systems, the study of gait can reveal early changes in functional performance $[2,3]$. With the loss of strength, decrease in deceleration control of the upper segments of the trunk in

\footnotetext{
* Correspondence: suely.roizenblatt@unifesp.br

${ }^{2}$ Department of Internal Medicine, Universidade Federal de Sao Paulo (UNIFESP), Rua Angelina Maffei Vita 670. CEP:01455070, Sao Paulo, SP, Brazil Full list of author information is available at the end of the article
}

relation to the lower ones occurs particularly in the anteroposterior (AP) plane [1]. The control of the shoulder to head acceleration is less effective in older women than in men, suggesting a strain in the ability to exploit the cervical joints to attenuate the AP acceleration [4]. Furthermore, instead of using the ankle muscles to maintain balance, there is a greater demand from the muscles around the hips and thoracolumbar region $[1,5,6]$.

As posture tends to flexion, the progressive forward displacement of the center of mass (CM) near the stability limit requires compensation to maintain gait speed [7]. The kinematics analysis of the pelvis and lower extremities using a 3-dimensional video-based motion

(c) The Author(s). 2021 Open Access This article is licensed under a Creative Commons Attribution 4.0 International License, which permits use, sharing, adaptation, distribution and reproduction in any medium or format, as long as you give appropriate credit to the original author(s) and the source, provide a link to the Creative Commons licence, and indicate if changes were made. The images or other third party material in this article are included in the article's Creative Commons licence, unless indicated otherwise in a credit line to the material. If material is not included in the article's Creative Commons licence and your intended use is not permitted by statutory regulation or exceeds the permitted use, you will need to obtain permission directly from the copyright holder. To view a copy of this licence, visit http://creativecommons.org/licenses/by/4.0/. 
system has shown that the retroversion of the pelvis is the resulting compensation for the increased kyphosis acquired over time. Studies on the role of the sagittal alignment in gait have confirmed that compensation mechanisms of increased kyphosis in the elderly include a sequence of events, such as posterior pelvic tilting, increase in hip extension, then knee flexion and increase ankle dorsiflexion [8]. A study of the sagittal alignment and gait speed influences on falls of middle-aged and older males has shown that falls in the previous year was associated with the reduction in lumbar lordosis, sacral slope, and decrease of the gait speed [9].

When accelerometers were incorporated into clinical practice as an instrumental method to objectively detect small changes in the functioning of postural control in older adults [10], there was a progress in the assessment of gait adaptive mechanisms that compensate for changes in posture. The advantage of these portable devices is the possibility of recording spontaneous movements out of the laboratory environment. For review on the advantages of accelerometers as a method of early detection of alterations in balance in older people see Leirós-Rodríguez et al., 2019 [11]. Very few studies have used accelerometers to access the gait responses to the body's forward displacement of the CM in older adults in a free-living context. Groot et al., demonstrated that the correcting responses result in an increase in the risk of falling due to lower stability of the gait, and a more irregular trunk acceleration [12]. Lack of coordination linking acceleration variability between the trunk and feet in a constrained gait have been demonstrated by accelerometry, even in healthy older fallers, when subjected to a protocol of gait analysis in a treadmill with variable speed [13].

Considering the value of early physical ability improvement on the prevention of falls in older adults [14], and the lack of studies on the association of sagittal alignment and accelerometry analysis of gait, this study was conducted to investigate the correlation of the spine and pelvis alignment with changes in accelerometer-based gait parameters in asymptomatic women aged 60 years or older. The primary objective was to evaluate the correlation between spine and pelvic angles in performance tests and accelerometry parameters. The secondary objective was to study the correlation of performance tests and accelerometry.

\section{Methods}

\section{Participants}

In this cross-sectional study of a sample of women aged 60 years or older, who were physically active and independent from assistance or assistive tools, were consecutively recruited from the Open University of the Third Age of the XXXXXXXX. Inclusion criteria comprised good cognitive condition (MiniMental State Examination (MMSE) score > 24 [15], Body Mass Index below $30 \mathrm{~kg} /$ $\mathrm{m}^{2}$, and robustness [16]. Exclusion criteria comprised the reporting of falls in the previous year, complaints of back pain or impaired gait, $\geq 7$ points in the ClinicalFunctional Vulnerability Index (IVCF-20) [16], scoliosis Cobb angle $>20^{\circ}$; skeletal abnormalities, neurological or musculoskeletal disabilities that interfered with gait; uncontrolled diabetes mellitus; alcoholism; history of spine surgery, and fractures or prosthesis implants in the lower limbs.

The research was approved by the Ethical Committee of XXXX (\#824.155), and written informed consent was obtained from each participant after the explanation of the objective and methodology of the study. During the first visit, participants answered questionnaires regarding cognitive condition, vulnerability, falls, and self-reported exercise adherence. The answers were evaluated by a rheumatologist (XX) and in case of eligibility for the study, the participants were sent to radiological evaluation of the sagittal balance, carried out by a trained radiologist (XX). In a second visit, performance tests and accelerometry recordings were conducted by a trained physical therapist (XXX).

\section{Questionnaires}

The IVCF-20 was used to assess vulnerability. The IVCF-20 is a 20 question multidimensional inventory that covers aspects of the elderly's health conditions, which includes age, health self-perception, functional disabilities, cognition, mood, mobility, communication, and multiple comorbidities. The maximum score is 40 points and the higher the value obtained, higher is the elderly's risk for clinical-functional vulnerability. In our study, robustness was defined for scores $<7$ as reported for the Brazilian elderly [16].

Cross-cultural adaptation of the Falls Efficacy ScaleInternational (FES-I) for Brazilians was used to assess the fear of falling during the previous year. This 16question inventory inquiring "how concerned are you about the possibility of falling" is rated as not at all, somewhat, fairly, and very concerned. The total score ranges from 16 to 64 points, being the higher values indicative of higher concern about falling [17].

Self-reported exercise adherence was assessed by the weekly frequency of reported aerobic or resistance training exercises in the previous month. According to the answers, subjects were considered as highly active (physical exercises at least 3 days a week), moderate (at least once a week) and inactive (less than once a week).

\section{Performance tests}

Participants were subjected to two sessions of a $10-\mathrm{m}$ walk at a comfortable speed, which was measured in 
meters/second. The tests were performed on a level and clear $30-\mathrm{m}$ corridor, with $1.5-\mathrm{m}$ space for acceleration and deceleration, and without encouraging words. Gait speed between $0.90-1.42 \mathrm{~m} / \mathrm{s}$ has been considered adequate for the walking economy during the ageing process $[18,19]$. Berg Balance Scale validated to Brazilian Portuguese [20] was used to assess functional balance performance; and was based on 14 questions with answers ranging from 0 to 4 points. Total scores of 0 to 20 represent balance impairment, of 21 to 40 indicate acceptable balance, and of 41 to 56, good balance [21].

Timed Up-and-Go (TUG) was also carried out for functional performance. Participants, wearing their usual footwear, were seated on a standard chair with solid seat, with their backs supported by a flat backrest, and their arms supported by armrests. At the evaluator's instruction, they had to stand up, walk a $3 \mathrm{~m}$-distance in a straight line, in a comfortable speed, cross a mark on the floor, then turn around $180^{\circ}$, walk back, and sit down again. There was one practice session immediately before the test session was performed. The evaluator initiated the chronometer at the moment the participants stood up, and stopped it only when they were seating on the chair with their arms and back supported again. TUG values over $12.47 \mathrm{~s}$ are considered as predictive of falls for the Brazilian older adults [22]..

\section{Radiological evaluation}

For Pelvic Incidence, complete overlap between the femoral heads was required. Sagittal images were obtained with subjects in the orthostatic position, with upper limbs flexed, hands on the shoulders in $30^{\circ}$ flexion, knees extended, and looking straight ahead. The image scope was from the cervical spine to the femoral heads, and the distance from source-to-film was $2.3 \mathrm{~m}$ [23].

Thoracic Cobb angle was computed as the angle formed between the two straight lines that were orthogonal to the upper endplate of T4 to the endplate of T12. For Lumbar Cobb the reference points were the upper endplate of L1 to the lower endplate of L5 [24]. Thoracic Cobb mean values for older Brazilian women are $43.1^{\circ} \pm$ $13.6^{\circ}$, and for the Lumbar Cobb, $-41.7^{\circ} \pm 11.9^{\circ}$ [25].

Pelvic Incidence angle was defined by a line drawn from the center of the femoral heads to the midpoint of the sacral endplate, and a line perpendicular to the center of the sacral endplate. Pelvic Tilt was defined as the angle subtended by a vertical reference line originating from the center of the femoral head and the midpoint of the sacral endplate. Sacral Slope was defined as the angle subtended by a horizontal reference line and the sacral endplate line. The reported mean reference values for Brazilians, older than 60 years were: Pelvic Incidence angle of $50.9^{\circ} \pm 6.6^{\circ}$, Sacral Slope of $37.4^{\circ} \pm 5.1^{\circ}$, and Pelvic Tilt of $13.8^{\circ} \pm 5^{\circ}[26]$.

\section{Accelerometry}

We used the MiniMod DynaPort ${ }^{\mathrm{Tm}}$ (McRoberts, Netherlands) with a signal acquisition frequency of 100 $\mathrm{Hz}$, in a range of variation of $\pm 2 \mathrm{~g}$ in a 30 -m walking trial [27]. The device was attached to a belt that was placed firmly at the point behind the spinal process of L3. This point is easily located and it is convenient for global measure of walking parameters, due to its proximity to the $\mathrm{CM}$ in the upright stance and during walking [28, 29]. Gait was assessed in a 30-m walk distance held at comfortable speed, with a $1.5-\mathrm{m}$ space for acceleration and deceleration, and without encouraging words.

Data was collected by MiniMod Acquire (MIRA ${ }^{\mathrm{m}}$; McRoberts, Netherlands) and processed using iGait, which is an open-source software from MatLab ${ }^{\text {tm }}$ environment [30]. After alignment correction, gait data extracted in the temporal domain included: Stride Regularity, Gait Symmetry, Root Mean Square (RMS) value in the anteroposterior (AP), vertical (V), and medio-lateral $(\mathrm{ML})$ planes. The square root values of the three planes were normalized to the average value of square root/RMS. Step and Stride Regularities were defined as the correlation between the original acceleration signal and the acceleration signal phase shifted to the average step and stride time, respectively [28-30]. Gait Symmetry was defined as the difference between the consistency of strides and steps in the accelerometer waveforms. Step Length was calculated dividing the 30$\mathrm{m}$ walk distance by the number of peaks of acceleration detected by the accelerometer during the foot contact with the ground.

\section{Statistical analysis}

A sample of 38 elderly women allowed detection of a correlation of 0.44 or more between radiographic and accelerometer-derived data with an alpha of 0.05 and power of $80 \%$ [31].

Mean and standard deviation (SD) were used for data with parametric distribution whereas median and interquartile range (IQR) were used for the non-parametric data. The Spearman's rank correlation coefficient was used to calculate correlations between the angles of the spine and pelvis with clinical, functional and accelerometer-derived parameters.

Multivariate regression was used to evaluate the existing association of age with radiological and accelerometer-derived data of normal distribution. Independent variables tested were age, height, weight, Thoracic Cobb, Lumbar Cobb, Sacral Slope, Pelvic Tilt, whereas the dependent variables tested were, RMS, Step Length, Stride Regularity and Gait Symmetry in all planes. Data were tabulated and analyzed using SPSS Statistics for Windows, Version 22.0, IBM Corp and the significance was set at $5 \%$. 


\section{Results}

The sample of 54 women, aged 60 years and older, who met inclusion criteria and agreed to participate in the protocol was selected among 220 volunteers (Fig. 1).

The characteristics of the sample are described in Table 1. In comparison to what has been reported for Brazilians older than 60 years [26], we observed an increase in the following pelvic angles mean \pm SD: Pelvic Incidence $\left(50.9^{\circ} \pm 6.6^{\circ}\right.$ vs. $\left.57.9^{\circ} \pm 11.5^{\circ}\right)$, Pelvic Tilt $\left(13.8 \pm 5^{\circ}\right.$ vs. $\left.17.4 \pm 8.0^{\circ}\right)$ and Sacral Slope $\left(37.4^{\circ} \pm 5.1^{\circ}\right.$ vs. $40.4^{\circ} \pm 7.8^{\circ}$. In comparison to the literature on older women [25], there was an increase in mean \pm SD Thoracic Cobb $\left(43.1^{\circ} \pm 13.6^{\circ}\right.$ vs. $\left.47.4^{\circ} \pm 9.7^{\circ}\right)$ and Lumbar $\operatorname{Cobb}\left(-41.7^{\circ} \pm 11.9^{\circ}\right.$ vs. $\left.-46.3^{\circ} \pm 7.5^{\circ}\right)$.

Regarding self-reported exercise adherence, 21 (38.8\%) of the women were considered as inactive, 27 (50.0\%) as active, and 6 (11.1\%) as highly active. Even though report of falls in the previous year was one of the exclusion criteria, 30 participants (55.5\%) scored above 23 in FES-I, which has been associated with the adoption of strategies to avoid falls [17].

In the performance tests, $43(79.6 \%)$ of the subjects presented TUG values below the predictive cut-off for falls for older Brazilians, which corresponds to $12.47 \mathrm{~s}$ [22]. As shown in Table 1, the median TUG value was 9.4 with IQR of 2.2. The median Berg Balance Scale score was 50 with IQR of 4, and a minimum score of 37 [20]. Two participants (3.7\%) scored between 20 and 41,

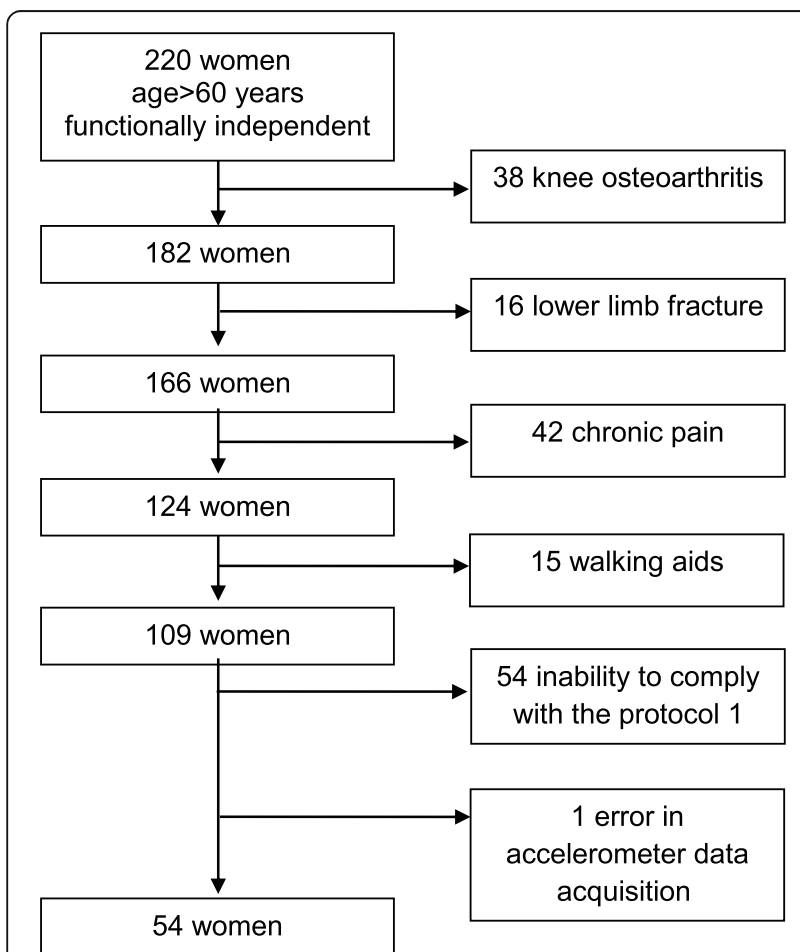

Fig. 1 Inclusion of participants in the study
Table 1 Sample characteristics

\begin{tabular}{lllll}
\hline $\mathbf{N = 5 4}$ & $\begin{array}{l}\text { Mean } \\
\text { or } \\
\text { Median }\end{array}$ & $\begin{array}{l}\text { SD } \\
\text { IQR }\end{array}$ & Minimum & Maximum \\
& 72.33 & 6.14 & 61.00 & 85.00 \\
\hline Age (years) & 151.52 & 6.21 & 140.00 & 165.00 \\
Height (m) & 59.82 & 8.97 & 44.00 & 80.00 \\
Weight (kg) & 26.48 & 4.04 & 24.00 & 30.00 \\
MMSE & 24.00 & 7.25 & 17.00 & 45.00 \\
FES-I (median [IQR]) & 50.00 & 4.00 & 37.00 & 56.00 \\
Berg scale (median [IQR]) & 9.43 & 2.20 & 6.57 & 15.45 \\
TUG (sec) (median [IQR]) & 1.10 & 0.19 & 0.57 & 1.54 \\
Gait speed (m/sec) & 47.43 & 9.67 & 17.00 & 62.00 \\
Thoracic Cobb (degrees) & 46.31 & 7.54 & 19.00 & 55.00 \\
Lumbar Cobb (degrees) & 47.91 & 11.46 & 39.40 & 85.78 \\
Pelvic Incidence (degrees) & 57.90 & 49.41 \\
Sacral Slope (degrees) & 40.41 & 7.79 & 30.17 & 46.00 \\
Pelvic Tilt (degrees) & 17.42 & 8.03 & 0.00 & \\
\hline Comfortablegait speed & & & & \\
\hline
\end{tabular}

Comfortable gait speed in 10-m gait test

$S D$ standard deviation, IQR interquartile range, MMSE MiniMental State

Examination, FES-I Fall Efficacy Scale -International, TUG Timed up and Go

which is considered an acceptable balance. Mean \pm SD comfortable gait speed obtained in the 10 -m walk test was $1.10 \pm 0.19 \mathrm{~m} / \mathrm{s}$ and the one obtained by accelerometry was $1.09 \pm 0.19$, with a correlation $r_{\mathrm{S}}$ of $0.679,(p<$ 0.01 ) between them. Comfortable gait speed in the $10-\mathrm{m}$ walk test negatively correlated with TUG $(-0.620$; $p<0.01)$ and with Thoracic Cobb $(-0.341 ; p<0.05)$.

Correlations of spine and pelvis angles were assessed with FES-I, performance tests, and with accelerometer-derived data. Significant findings are shown in Tables 2 and 3, respectively. Complementarily, significant correlations of FES-I and performance tests with accelerometer-derived data were found in the AP plane are (Table 4). Mean \pm SD values of the accelerometer-derived parameters that presented significant correlations with sagittal alignment data (Table 3) and performance tests (Table 4) were: RMS $(0.17 \pm 0.04$, range $0.06-0.25 \mathrm{~g})$, Step Length $(0.59 \pm$ 0.08 , range $0.34-0.73 \mathrm{~m})$, Stride Regularity $(0.81 \pm 0.10$ range $0.61-0.90)$, and Gait Symmetry $(6.04 \pm 3.04$, range $0.3-0.97)$. Pelvic Tilt angle and accelerometerderived variables in the $\mathrm{ML}$ and $\mathrm{V}$ planes were not included in the Tables due to the lack of correlation with the other parameters.

In the multiple regression analysis, age accounted for $12.3 \%$ of the variance of RMS in AP and the overall regression model was $\mathrm{F}(1,53)=7.43, p=0.009, \mathrm{R}^{2}$ coefficient of 12.3 , with a positive independent contribution of age (unstandardized beta coefficient of 0.002). In addition, there was a slight correlation of age with RMS in $\mathrm{AP}(-0.351 ; p<0.01)$. 
Table 2 Correlations of spine and pelvis angles with FES-I and performance tests

\begin{tabular}{lllll}
\hline $\boldsymbol{N}=\mathbf{5 4}$ & Thoracic Cobb & Lumbar Cobb & Pelvic Incidence & Sacral Slope \\
\hline Gait speed & $-0.341^{*}$ & -0.130 & -0.139 & 0.178 \\
FES-I & +0.242 & +0.199 & $+0,149$ & $-0.339^{*}$ \\
TUG (sec) & $+0.341^{*}$ & -0.030 & -0.039 & +0.178 \\
Berg Balance Scale & +0.197 & +0.187 & +0.269 & $+0.367^{* *}$ \\
\hline
\end{tabular}

Comfortable gait speed in 10-m gait test

FES - I Fall Efficacy Scale - International, TUG Timed Up and Go

Spearman correlations: ${ }^{*} p<0.05,{ }^{* *} p<0.01$

\section{Discussion}

This study was proposed to provide new information on the relationship between radiographic measures of spinal alignment and parameters of gait extracted from accelerometry in robust, community-dwelling women aged 60 years and older. The results revealed that Sacral Slope, rather than Lumbar Cobb, positively correlated with Step Length and weakly with RMS and Stride Regularity in the AP plane. Furthermore, weak correlations of Sacral Slope were obtained with FES-I and Berg Balance Scale. The underlying implications of such correlations, albeit weak, need to be reported.

During walking, the tendency is to choose a gait speed that optimizes the body movement and minimizes the energy cost per distance. Walking faster or slower requires more energy and increases the magnitude of speed variation due to gait instability [32]. The gait speed of our sample was within the expected range for a comfortable gait speed in a $10-\mathrm{m}$ walk by robust women between 60 and 79 years $[18,33]$. The association of age with slowing of temporal gait measurements still remains controversial [34-36]. It has been suggested that a "cautious gait" pattern, is a marker of an underlying pathology and not an age-related process [37]. While low walking speed has a negative effect on stability, short Step Length has a positive effect on it [18].

Kerrigan et al., 2001 observed that in a group of robust older adults (10 men and 13 women) with similar mean age of our sample, fallers presented a shorter Step Length than non-fallers $(0.49 \pm 0.08 \mathrm{~m}$ vs, $0.61 \pm 0.06 \mathrm{~m})$. The Step Length mean value obtained in our group of non-faller older women was $0.59 \pm 0.08 \mathrm{~m}$. The slight difference may be attributed to the inclusion of men in their sample [3]. Even though we only included non- faller older women in our research, FES-I median score of 25 indicates their substantial fear of falling [17]. In TUG test, $79.6 \%$ of the sample exhibited values below $12.47 \mathrm{~s}$, which has been considered as a predictive cutoff for falls for older Brazilians [22]. The finding of negative correlations between FES-I and TUG with Step Length supports the hypothesis that shortening of the Step Length corresponds to a postural adaptation to increase time spent in double support for maintenance of balance [34, 38]. Postural control and balance are important aspects of gait stability and are necessary to reduce the chances of falling [39].

Hyperkyphosis has been considered as the earliest body posture change throughout ageing, both in healthy women [6] and men [40]. The impact of the forward displacement of the $\mathrm{CM}$ on gait, related to a hyperkyphotic posture, was confirmed in the present study by the negative correlation between Thoracic Cobb and Gait Speed in the $10-\mathrm{m}$ walk test, and with the positive correlation with TUG. For the maintenance of the sagittal alignment, thoracic kyphosis compensation by retroversion of the pelvis and sacral verticalization would be expected when Pelvic Incidence allows the CM projection not to exceed the base of support [41]. The stress that hyperkyphosis poses to the gait yields in decline in the walking economy [18].

Furthermore, the pelvic three-dimensional movement corresponds to a kinematic mechanism that maintains the efficient translation of the $\mathrm{CM}$ and pelvic anteversion-retroversion movement influence on the Step Length [42]. How reduction in pelvic rotation contributes to the "cautious gait" in older adults still remains unknown. The negative correlation between FES-I and Sacral Slope, albeit weak, suggests that the fear of

Table 3 Correlations of spine and the pelvis angles with accelerometer-derived data in the anteroposterior plane

\begin{tabular}{lllll}
\hline $\mathbf{N}=\mathbf{5 4}$ & Thoracic Cobb & Lumbar Cobb & Pelvic Incidence & Sacral Slope \\
\hline RMS & +0.017 & $+0.392^{* *}$ & $+0.318^{*}$ & $+0.439^{* *}$ \\
Step Length & +0.124 & $+0.405^{* *}$ & $+0.430^{* *}$ & $+0.615^{* *}$ \\
Stride Regularity & +0.091 & $+0.345^{*}$ & +0.260 & $+0.475^{* *}$ \\
Gait symmetry & +0.107 & -0.102 & -0.248 & -0.150 \\
\hline
\end{tabular}

RMS Root Mean Square of acceleration during walking (center of mass displacement)

Spearman correlations: ${ }^{*} p<0.05,{ }^{* *} p<0.01$ 
Table 4 Correlations of accelerometer-derived data in the anteroposterior plane with FES-I and performance tests

\begin{tabular}{lllll}
\hline $\boldsymbol{N}=\mathbf{5 4}$ & RMS & $\begin{array}{l}\text { Step } \\
\text { Length }\end{array}$ & $\begin{array}{l}\text { Stride } \\
\text { Regularity }\end{array}$ & Gait symmetry \\
\hline Gait speed & 0.236 & 0.035 & 0.118 & 0.005 \\
FES-I & $+0.407^{* *}$ & $-0.414^{* *}$ & $+0.561^{* *}$ & $-0.318^{*}$ \\
TUG (sec) & $+0.313^{*}$ & $-0,367^{*}$ & $+0.381^{*}$ & $-0.489^{* *}$ \\
Berg Balance Scale & +0.103 & +0.249 & +0.105 & -0.031 \\
\hline
\end{tabular}

Comfortable gait speed in 10-m gait test

RMS Root Mean Square of acceleration during walking (center of mass

displacement), FES -I Fall Efficacy Scale - International, TUG Timed Up and Go

Spearman correlations: ${ }^{*} p<0.05,{ }^{* *} p<0.01$

falling was greater in those with a verticalized sacrum. The retroversion of the pelvis and the sacrum verticalization impose a maximum hip extension impairing the ankle push-off reaction, with a negative effect on the displacement of the CM which oscillates back and forth from the support base during walking $[3,12,43]$.

In our sample of older women, without gait complaints, there was an increase in the expected mean value of Pelvic Incidence and Sacral Slope [26]. Notwithstanding, a Sacral Slope between $35^{\circ}$ and $45^{\circ}$, as obtained in our sample, is described as representative of a healthy balanced spine [44]. Pelvic Incidence values below $44^{\circ}$ are related to a decrease in Sacral Slope and flattening of Lumbar Lordosis, whereas values above $62^{\circ}$ have the opposite effect. Sacral Slope is the key parameter contributing to the sagittal curvature. The degree of the Sacral Slope determines the position of the lumbar spine, since the sacral plateau forms the base of the spine and therefore may provide the possibility of balance [45]. Lower Pelvic Incidence results in lower Sacral Slope and lower degree of Lumbar Lordosis [46]. Even though this relationship is independent of the ageing process, parameters of the sagittal alignment of the spine and pelvis should be taken into account in studies of gait even for the robust older adults.

The detrimental effect of sagittal imbalance on gait performance has been evidenced by Miyazaki et al., in a sample of asymptomatic older men with an age range similar to our sample [40]. Our finding of a positive Berg Balance Scale correlation with Pelvic Incidence and Sacral Slope, although weak, is in line with the positive effect of high Pelvic Incidence and Sacral Slope on balance. The Berg Balance Scale was originally developed to assess the functional performance of balance through functional tasks that require equilibrium in older people. The weak correlation that we obtained might be attributed to the discrepancy between the static characteristic of most tasks assessed by Berg Balance Scale and the dynamic nature of walking [47].

The correlation of our sagittal alignment data with accelerometer-derived gait parameters suggests early difficulty in controlling the displacement of the $\mathrm{CM}$ in the AP plane, Ideally, a perfect sagittal alignment occurs when the body weight is positioned along a line slightly behind the rotation axis of the two femoral heads. Low values of Sacral Slope and Lumbar Cobb angles limit the pelvis movements, what result in an inefficient balance control [48], as shown in our study by the negative correlation of Sacral Slope with FES-I and positive correlation with Step Length. Further positive correlations, albeit weak, are in line with this finding, such as Pelvic Incidence and Lumbar Lordosis correlation with Step Length and RMS in AP, and Sacral Slope with both RMS and Stride Regularity in AP.

Early alterations found in AP plane result in a loss in propulsion and braking phases of gait in older women with preserved mobility, suggesting a correlation between shortening of Step Length and gait destabilization $[2,29]$. Considering that the major component of gait occurs in the AP plane, it becomes necessary to increase the effort at this plane to keep the progression of the gait [49].. Increased fear of falling requires more energy consumption to support the AP displacement due to the increase in step rate. Shortening of the Step Length is associated with a decline in the walking economy and irregular body acceleration in the AP plane, which is the major component of gait [18, 32]. Our data shows negative correlation of FES-I with Step Length, but a positive correlation of FES-I with Stride Regularity in AP, suggesting preservation of the functional ability to control the step sequence. The increase in energy required to sustain the walking forward is reflected by the positive correlation of FES-I with RMS in AP plane. Acceleration RMS estimates the magnitude of the variation of the gravitational potential energy of the $\mathrm{CM}$ that is exchanged for forward kinetic energy. The increase in energy consumption can be expressed as an increase in RMS [50].

Age related decline in walking economy is associated with the adoption of an increased gait rate and progressive irregular body acceleration in the horizontal plane. A higher gait rate is a consequence of the shortening of the Step Length which characterizes an unstable walking [18]. The negative correlations of both FES-I and TUG with Gait Symmetry in AP suggest that impaired Gait Symmetry might also be a predictor of future falls [51]. The value of TUG remains in the fact that it corresponds to the challenge in the energy required to adopt different postures and change of directions.

Our data shows the impact of the insufficient compensation of the sagittal alignment by the upper or lower body segments on the gait pattern [45], even in robust older women, However, there are several limitations in this study. First, the cross-sectional design and consecutive sampling prevent generalization of our findings. 
However, our decision to enroll every single participant who met inclusion criteria until the sample size was reached was based on the higher reliability of the results than we would get with subjects chosen the by the investigator's convenience sampling. This way, our results can be considered as useful guidelines for future studies. Second, since a longitudinal design is better suited for studies on the gait pattern in older adults, we intend to follow this sample of robust older women over time in order to detect the turning point when gait changes become symptomatic. Third, many of the correlations we found were not strong. Subtle gait changes that increase the risk of falls might not have been accurately recorded. A longitudinal study will enable confirmation of the relevance of the findings with weaker correlations, which are already supported by the literature. Fourth, potential measurement errors in the Cobb angle may be attributed to the variation within and between observers due to the poor visualization of the vertebral body limits; that are covered by overlying tissue densities, the presence of transition vertebra, variations related to the minor rotation of the subject between examinations, and the variation in the same subject. Lack of accuracy is more relevant for smaller angles $\left(<10^{\circ}\right)$, which was not the case for the present study.

Even with these limitations, our results support the hypothesis that there is a correlation between the spine and pelvic angles with the performance tests and accelerometry parameters. Sacral Slope and Lumbar Cobb positively correlate with Step Length. Further weak correlations of sagittal alignment were obtained with accelerometry-derived parameters, however considering the complexity of the walking mechanics that influence gait, we would not expect that any single correlation would be particularly high in robust older women. The contribution of the Sacral Slope on impact absorption and variability of trunk movements during gait deserves further elucidation.

\section{Conclusions}

While we expected preserved walking conditions, gait alterations in the AP plane were detected and were correlated to lower Sacral Slope and Lumbar Lordosis. Our results have a possible application in the understanding of the early changes in the postural control during gait in robust older women.

Aknowledgments The authors thank all subjects who participated in this study and Associacao Fundo de Incentivo a Pesquisa for providing the accelerometer devices that were used in this research.

\section{Abbreviations}

AP: Anteroposterior; CM: Center of mass; FES-I: Falls Efficacy ScaleInternational; IQR: Interquartile range; MMSE: MiniMental State Examination;
IVCF-20: Clinical-Functional Vulnerability Index; RMS: Root mean square; SD: Standard deviation; TUG: Timed Up-and-Go

\section{Authors' contributions}

LMO: Participated in the in the elaboration of the research, data discussion and the article writing. Collection and data discussion and the article writing. SR: Participated in the study data collection, statistical analysis and the article writing. FDS and ARCF: Participated in the design and execution of the radiological evaluation of the participants, analyzed and interpreted the results and contributed in data discussion. AR: performed statistical analysis, drafted and critically revised the manuscript. VLS: Participated in the data discussion and the article writing. The authors read and approved the final version of the manuscript.

\section{Funding}

Not applicable.

\section{Availability of data and materials}

The datasets used in this study are available from the corresponding author on reasonable request.

\section{Declarations}

Ethics approval and consent to participate

The Institutional Research Ethics Committee approved the study, under registration number 824.155

\section{Consent for publication}

Participants read and signed informed consent forms at study enrollment.

\section{Competing interests}

The authors declare that they have no competing interests or other interests that might be perceived to influence the interpretation of the article.

\section{Author details}

${ }^{1}$ Rheumatology Division, Universidade Federal de Sao Paulo (UNIFESP), São Paulo, Brazil. ${ }^{2}$ Department of Internal Medicine, Universidade Federal de Sao Paulo (UNIFESP), Rua Angelina Maffei Vita 670. CEP:01455070, Sao Paulo, SP, Brazil. ${ }^{3}$ Department of Diagnostic Imaging, Universidade Federal de Sao Paulo (UNIFESP), São Paulo, Brazil. ${ }^{4}$ Medical Student Universidade Federal de Sao Paulo (UNIFESP), São Paulo, Brazil.

Received: 16 October 2020 Accepted: 25 May 2021

Published online: 12 June 2021

\section{References}

1. Van Emmerik RE, McDermott WJ, Haddad JM, Van Wegen EE. Age-related changes in upper body adaptation to walking speed in human locomotion. Gait Posture. 2005;22(3):233-9. https://doi.org/10.1016/j.gaitpost.2004.09.006.

2. Winter DA, Patla AE, Frank JS, Walt SE. Biomechanical walking pattern changes in the fit and healthy elderly. Phys Ther. 1990;70(6):340-7. https:// doi.org/10.1093/ptj/70.6.340.

3. Kerrigan DC, Lee LW, Collins JJ, Riley PO, Lipsitz LA. Reduced hip extension during walking: healthy elderly and fallers versus young adults. Arch Phys Med Rehabil. 2001;82(1):26-30. https://doi.org/10.1053/apmr.2001.18584.

4. Mazza C, losa M, Picerno P, Cappozzo A. Control of the upper body accelerations in young and elderly women during level walking. J Neuroeng Rehabil. 2008;5(1):30. https://doi.org/10.1186/1743-0003-5-30.

5. Daly RM, Rosengren BE, Alwis G, Ahlborg HG, Sernbo I, Karlsson MK. Gender specific age-related changes in bone density, muscle strength and functional performance in the elderly: a-10 year prospective populationbased study. BMC Geriatr. 2013;13(1):71. https://doi.org/10.1186/1471-231 8-13-71.

6. Drzal-Grabiec J, Snela S, Rykala J, Podgorska J, Banas A. Changes in the body posture of women occurring with age. BMC Geriatr. 2013;13(1):108. https:// doi.org/10.1186/1471-2318-13-108.

7. Sinaki M, Brey RH, Hughes CA, Larson DR, Kaufman KR. Balance disorder and increased risk of falls in osteoporosis and kyphosis: significance of kyphotic posture and muscle strength. Osteoporos Int. 2005;16(8):1004-10. https:// doi.org/10.1007/s00198-004-1791-2. 
8. Le Huec JC, Charosky S, Barrey C, Rigal J, Aunoble S. Sagittal imbalance cascade for simple degenerative spine and consequences: algorithm of decision for appropriate treatment. Eur Spine J. 2011;20(Suppl 5):699-703. https://doi.org/10.1007/s00586-011-1938-8.

9. Imagama S, Ito Z, Wakao N, Seki T, Hirano K, Muramoto A, et al. Influence of spinal sagittal alignment, body balance, muscle strength, and physical ability on falling of middle-aged and elderly males. Eur Spine J. 2013;22(6): 1346-53. https://doi.org/10.1007/s00586-013-2721-9.

10. Culhane KM, O'Connor M, Lyons D, Lyons GM. Accelerometers in rehabilitation medicine for older adults. Age Ageing. 2005;34(6):556-60. https://doi.org/10.1093/ageing/afi192.

11. Leirós-Rodríguez R, García-Soidán JL, Romo-Pérez V. Analyzing the Use of Accelerometers as a Method of Early Diagnosis of Alterations in Balance in Elderly People: A Systematic Review. Sensors (Basel). 2019;19:3883. https:// doi.org/10.3390/s19183883.

12. de Groot MH, van der Jagt-Willems HC, van Campen JP, Lems WF, Beijnen $\mathrm{JH}$, Lamoth CJ. A flexed posture in elderly patients is associated with impairments in postural control during walking. Gait Posture. 2014;39(2): 767-72. https://doi.org/10.1016/j.gaitpost.2013.10.015.

13. Craig JJ, Bruetsch AP, Huisinga JM. Coordination of trunk and foot acceleration during gait is affected by walking velocity and fall history in elderly adults. Aging Clin Exp Res. 2019;31(7):943-50. https://doi.org/10.1 007/s40520-018-1036-4.

14. Imagama S, Hasegawa Y, Matsuyama Y, Sakai Y, Ito Z, Hamajima N, et al. Influence of sagittal balance and physical ability associated with exercise on quality of life in middle-aged and elderly people. Arch Osteoporos. 2011; 6(1-2):13-20. https://doi.org/10.1007/s11657-011-0052-1.

15. Bertolucci PH, Brucki SM, Campacci SR, Juliano Y. The Mini-Mental State Examination in a general population: impact of educational status. Arq Neuropsiquiatr. 1994;52(1):1-7. https://doi.org/10.1590/S0004-282X19940001 00001.

16. Moraes EN, Carmo JA, Moraes FL, Azevedo RS, Machado CJ, Montilla DE. Clinical-functional vulnerability Index-20 (IVCF-20): rapid recognition of frail older adults. Rev Saude Publica. 2016;50(0):81. https://doi.org/10.1590/s15188787.2016050006963.

17. Camargos FF, Dias RC, Dias JM, Freire MT. Cross-cultural adaptation and evaluation of the psychometmianric properties of the falls efficacy scaleinternational among elderly Brazilians (FES-I-BRAZIL). Rev Bras Fis. 2010;14(3): 237-43. https://doi.org/10.1590/S1413-35552010000300010.

18. Valenti $G$, Bonomi AG, Westerterp KR. Body acceleration as indicator for walking economy in an ageing population. PLoS One. 2015;10(10):e0141431. https://doi.org/10.1371/journal.pone.0141431.

19. Schrack JA, Zipunnikov V, Simonsick EM, Studenski S, Ferrucci L. Rising Energetic Cost of Walking Predicts Gait Speed Decline With Aging. J Gerontol A Biol Sci Med Sci. 71:947-53. https://doi.org/10.1093/gerona/glw002.

20. Miyamoto ST, Lombardi Junior I, Berg KO, Ramos LR, Natour J. Brazilian version of the Berg balance scale. Braz J Med Biol Res. 2004;37(9):1411-21. https://doi.org/10.1590/S0100-879X2004000900017.

21. Berg KO, Maki BE, Williams JL, Holliday PJ, Wood-Dauphine SL. Clinical and laboratory measures of postural balance in an elderly population. Arch Phys Med Rehabil. 1992;73(11):1073-80.

22. Alexandre TS, Meira DM, Rico NC, Mizuta SK. Accuracy of timed up and go test for screening risk of falls among community-dwelling elderly. Rev Bras Fis. 2012;16(5):381-8. https://doi.org/10.1590/S1413-35552012005000041.

23. Mac-Thiong JM, Roussouly P, Berthonnaud E, Guigui P. Sagittal parameters of global spinal balance: normative values from a prospective cohort of seven hundred nine Caucasian asymptomatic adults. Spine (Phila Pa 1976). 2010;35:E1193-8. https://doi.org/10.1097/BRS.0b013e3181e50808.

24. Furlanetto TS, Sedrez JA, Candotti CT, Loss JF. Reference values for cobb angles when evaluating the spine in the sagittal plane: a systematic review with meta-analysis. Motricidade. 2018;14(2-3):115-28. https://doi.org/10. 6063/motricidade.10890

25. Gasparotto LPR, Falsarella GR, Coimbra AMV. Lumbar spine angular measures in older people: comparison between two radiographic analysis strategies. Fisioter Pesqui [online]. 2016;23(4):388-93. https://doi.org/10.1 590/1809-2950/15932723042016.

26. Pratali RR, Nasreddine MA, Diebo B, Oliveira C, Lafage V. Normal values for sagittal spinal alignment: a study of Brazilian subjects. Clinics (Sao Paulo). 2018;73:e647. https://doi.org/10.6061/clinics/2018/e647.

27. Van Hees VT, Slootmaker SM, De Groot G, Van Mechelen W, Van Lummel RC. Reproducibility of a triaxial seismic accelerometer (DynaPort). Med Sci
Sports Exerc. 2009;41(4):810-7. https://doi.org/10.1249/MSS.0b013e31818ff63 6.

28. Kobayashi H, Kakihana W, Kimura T. Combined effects of age and gender on gait symmetry and regularity assessed by autocorrelation of trunk acceleration. J Neuroeng Rehabil. 2014;11(1):109. https://doi.org/10.1186/1 743-0003-11-109.

29. Kobsar D, Olson C, Paranjape R, Barden JM. The validity of gait variability and fractal dynamics obtained from a single, body-fixed triaxial accelerometer. J Appl Biomech. 2014;30(2):343-7. https://doi.org/10.1123/ja b.2013-0107.

30. Yang $\mathrm{M}$, Zheng $\mathrm{H}$, Wang $\mathrm{H}$, McClean $\mathrm{S}$, Newell D. iGAlT: an interactive accelerometer based gait analysis system. Comput Methods Prog Biomed. 2012;108(2):715-23. https://doi.org/10.1016/j.cmpb.2012.04.004.

31. Hulley SB, Cummings SR, Browner WS, Grady D, Newman TB. Designing clinical research : an epidemiologic approach. 4th ed. Philadelphia: Lippincott Williams \& Wilkins; 2013. Appendix 6C, page 79. ISBN-10: 0781722187, ISBN-13: 978-0781722186

32. Kavanagh JJ. Lower trunk motion and speed-dependence during walking. J Neuroeng Rehabil. 2009;6(1):9. https://doi.org/10.1186/1743-0003-6-9.

33. Brodie MA, Coppens MJ, Ejupi A, Gschwind YJ, Annegarn J, Schoene D, et al. Comparison between clinical gait and daily-life gait assessments of fall risk in older people. Geriatr Gerontol Int. 2017;17(11):2274-82. https://doi. org/10.1111/ggi.12979.

34. Callisaya ML, Blizzard L, McGinley JL, Srikanth VK. Risk of falls in older people during fast-walking--the TASCOG study. Gait Posture. 2012;36(3):510-5. https://doi.org/10.1016/j.gaitpost.2012.05.003.

35. Zijlstra A, de Bruin ED, Bruins N, Zijlstra W. The step length-frequency relationship in physically active community-dwelling older women. Eur J Appl Physiol. 2008;104(3):427-34. https://doi.org/10.1007/s00421-008-0795-6.

36. Park JH, Mancini M, Carlson-Kuhta P, Nutt JG, Horak FB. Quantifying effects of age on balance and gait with inertial sensors in community-dwelling healthy adults. Exp Gerontol. 2016;85:48-58. https://doi.org/10.1016/j.exger.2016.09.018.

37. Giladi N, Herman T, Reider-Groswasser II, Gurevich T, Hausdorff JM. Clinical characteristics of elderly patients with a cautious gait of unknown origin. Neurol. 2005;252(3):300-6. https://doi.org/10.1007/s00415-005-0641-2.

38. Osoba MY, Rao AK, Agrawal SK, Lalwani AK. Balance and gait in the elderly: a contemporary review. Laryngoscope Investig Otolaryngol. 2019;4(1):14353. https://doi.org/10.1002/lio2.252.

39. Mak TCT, Young WR, Chan DCL, Wong TWL. Gait stability in older adults during level-ground walking: the Attentional focus approach. J Gerontol B Psychol Sci Soc Sci. 2020;75:274-81. https://doi.org/10.1093/geronb/gby115.

40. Miyazaki J, Murata S, Horie J, Uematsu A, Hortobágyi T, Suzuki S. Lumbar lordosis angle (LLA) and leg strength predict walking ability in elderly males. Arch Gerontol Geriatr. 2013;56(1):141-7. https://doi.org/10.1016/j.a rchger.2012.09.004.

41. Dar G, Peleg S, Masharawi $Y$, et al. Sacroiliac joint bridging: demographical and anatomical aspects. Spine (Phila Pa 1976). 2005;30:E429-32. https://doi. org/10.1097/01.brs.0000172232.32082.e0.

42. Gimmon Y, Riemer R, Rashed H, Shapiro A, Debi R, Kurz I, et al. Age-related differences in pelvic and trunk motion and gait adaptability at different walking speeds. J Electromyogr Kinesiol. 2015;25(5):791-9. https://doi.org/1 0.1016/j.jelekin.2015.05.003.

43. McAndrew Young PM, Dingwell JB. Voluntary changes in step width and step length during human walking affect dynamic margins of stability. Gait Posture. 2012;36(2):219-24. https://doi.org/10.1016/j.gaitpost.2012.02.020.

44. Harding IJ. Understanding sagittal balance with a clinical perspective. Eur J Phys Rehabil Med. 2009;45(4):571-82 PMID: 20032917.

45. Boulay C, Tardieu C, Hecquet J, Benaim C, Mouilleseaux B, Marty C, et al. Sagittal alignment of spine and pelvis regulated by pelvic incidence: standard values and prediction of lordosis. Eur Spine J. 2006;15(4):415-22. https://doi.org/10.1007/s00586-005-0984-5.

46. Le Huec JC, Aunoble S, Philippe L, Nicolas P. Pelvic parameters: origin and significance. Eur Spine J. 2011;20(Suppl 5):564-71. https://doi.org/10.1007/ s00586-011-1940-1.

47. Laratta JL, Glassman SD, Atanda AA, Dimar JR, Gum JL, Crawford III CH, et al. The Berg balance scale for assessing dynamic stability and balance in the adult spinal deformity (ASD) population. J Spine Surg. 2019;5(4):451-6. https://doi.org/10.21037/jss.2019.09.15.

48. Bae JS, Jang JS, Lee SH, Kim JU. Radiological analysis of lumbar degenerative kyphosis in relation to pelvic incidence. Spine J. 2012:12(11): 1045-51. https://doi.org/10.1016/j.spinee.2012.10.011. 
49. van Schooten KS, Pijnappels M, Rispens SM, Elders PJ, Lips P, van Dieën JH. Ambulatory fall-risk assessment: amount and quality of daily-life gait predict falls in older adults. J Gerontol A Biol Sci Med Sci. 2015;70(5):608-15. https:// doi.org/10.1093/gerona/glu225.

50. Sekine M, Tamura T, Yoshida M, Suda Y, Kimura Y, Miyoshi H, et al. A gait abnormality measure based on root mean square of trunk acceleration. J Neuroeng Rehabil. 2013;10(1):118. https://doi.org/10.1186/1743-0003-10-118.

51. Mignardot JB, Deschamps T, Barrey E, Auvinet B, Berrut G, Cornu C, et al. Gait disturbances as specific predictive markers of the first fall onset in elderly people: a two-year prospective observational study. Front Aging Neurosci. 2014;6:22. https://doi.org/10.3389/fnagi.2014.00022.

\section{Publisher's Note}

Springer Nature remains neutral with regard to jurisdictional claims in published maps and institutional affiliations.

Ready to submit your research? Choose BMC and benefit from:

- fast, convenient online submission

- thorough peer review by experienced researchers in your field

- rapid publication on acceptance

- support for research data, including large and complex data types

- gold Open Access which fosters wider collaboration and increased citations

- maximum visibility for your research: over $100 \mathrm{M}$ website views per year

At $\mathrm{BMC}$, research is always in progress.

Learn more biomedcentral.com/submissions 